\title{
CONTRIBUIÇÕES DA TEORIA DE PIAGET PARA A FORMAÇÃO
} DE PROFESSORES

\section{Eliane Giachetto Saravali}

\section{Resumo}

O artigo discute a importância do conhecimento e do aprofundamento do referencial construtivista de Jean Piaget e suas principais contribuições para a formação do pedagogo e sua prática docente. Mediante a análise das respostas de estudantes de Pedagogia a um questionário avaliativo, o texto apresenta as percepções dos alunos sobre o estudo continuado da epistemologia genética.

\section{Palavras-chave}

Construtivismo; Formação de professores; Epistemologia genética

\section{CONTRIBUTION OF PIAGET'S THEORY TO THE FORMATION OF TEACHERS}

\begin{abstract}
The article discusses the importance of the knowledge and of the deepening of Piaget's constructivist referential and his main contributions to the formation of the pedagogue and his teaching practice. According to the analysis of the answers of Pedagogy students to an estimator questionary, the text presents the perceptions of the students about the continual study of the genetic epistemology.
\end{abstract}

\section{Keywords}

Constructivism; Formation of teachers; Genetic epistemology 


\section{INTRODUÇÃO}

A obra de Jean Piaget (1896-1980) teve grande influência na educação brasileira principalmente nas décadas de 70 e 80. Grande parte das discussões nos ambientes escolares concentrava-se nos trabalhos de Emília Ferreiro e nos processos cognitivos envolvendo a alfabetização. Nesse percurso, infelizmente, não se viu um aprofundamento e estudo continuado da teoria piagetiana, mas sim uma simplificação exagerada dos pressupostos construtivistas, uma transposição para a sala de aula de aspectos epistemológicos tratados pelo autor (como se a teoria estivesse voltada para questões educacionais), e um modismo exacerbado e eufórico em relação à idéia de construção do conhecimento.

Foi dessa forma que nossos professores acessaram a obra de Piaget. É evidente que algo assim não consegue sustentar-se por muito tempo, nem sobreviver ao próximo “modismo” que os ventos novos trazem. Assim, sem nem mesmo conhecê-la, os professores, as escolas e órgãos responsáveis pela educação, começaram a fazer a substituição da teoria piagetiana por outra(s) teoria(s) que pudesse resolver as questões que os inquietavam.

Infelizmente, uma das fortes características que norteiam as discussões em educação são esses "modismos" transitórios que privilegiam "novos autores" por algum tempo, tornando "alienígenas" e ultrapassados aqueles que não os lêem, não os citam, mesmo que se saiba de antemão que tais autores nem sempre trazem discussões novas. Nesse sentido, é comum vermos que a obra piagetiana é vista hoje como algo ultrapassado, defasado e perfeitamente substituível o que, a nosso ver, constitui um paradoxo, pois: como é possível negar aquilo que não se conhece?

Nesse artigo, pretendemos discutir sobre a atualidade da teoria construtivista, tão mal lida e mal compreendida, mostrando como um estudo aprofundado e contínuo desse referencial pode ser importante para a formação do pedagogo e para o trabalho do professor em sala de aula. Faremos isso a partir de dados obtidos junto a alunos do curso de Pedagogia que cursaram uma disciplina específica sobre a teoria piagetiana.

\section{PIAGET E A EDUCAÇÃo}

Jean Piaget era formado em Ciências Naturais e procurou encontrar uma explicação biológica para uma pergunta que norteou todo o seu trabalho: Como o homem atinge 
patamares de conhecimento mais avançados? Dessa forma, seu intuito era explicar a aquisição do conhecimento. Essa explicação buscou atingir um caráter universal, pois o homem que Piaget identifica não é alguém em específico: o homem da classe alta, ou da favela, mas um homem hipotético, universal que sintetiza todas as características e possibilidades dos outros homens - trata-se de um sujeito epistêmico.

Nessa busca constante, Piaget realizou inúmeras pesquisas em mais de cinco décadas, procurando explicações e analisando o pensamento dos sujeitos com os quais trabalhava, propondo problemas e investigando a gênese de diferentes noções a partir da forma como os indivíduos resolvem os desafios do meio que lhe são impostos.

Para chegar ao pensamento do adulto, Piaget recorreu ao pensamento infantil, ou seja, não era possível que os adultos recuperassem toda a gênese dos diferentes conceitos que construíram; portanto trabalhar com as crianças e depois com adolescentes permitia o acompanhamento da evolução do pensamento até sua maior elaboração, na fase adulta. Essa longa investigação permitiu ao autor descobrir características peculiares do nosso desenvolvimento, sobretudo do pensamento infantil que é qualitativamente diferente do pensamento adulto.

Para Piaget (1966), a inteligência é um caso particular da adaptação biológica constituindo-se essencialmente numa organização, permitindo a estruturação do universo. $\mathrm{O}$ sujeito avança na medida em que se adapta às situações impostas pelo meio, criando instrumentos para vencer os obstáculos. Nessa interação há dois importantes mecanismos: a assimilação e a acomodação. A assimilação permite a incorporação da informação aos esquemas que o indivíduo já possui e a acomodação consiste na modificação dos esquemas em função das resistências que o objeto a ser assimilado impõe ao sujeito. Para que ocorra adaptação à nova situação deve haver o equilíbrio entre a incorporação e a modificação, ou seja, entre a assimilação e a acomodação.

Durante as inúmeras assimilações e acomodações que vamos realizando em nossas sucessivas e constantes interações com o meio, avançamos e procuramos sempre a busca de um equilíbrio, até que um novo problema torne a nos desafiar desequilibrando-nos novamente. 
Ao longo desse desenvolvimento contínuo, é importante destacar que a qualidade das trocas com o meio físico e social são sumariamente importantes, destacando-se também que o sujeito deve estar interessado e motivado para vencer os desafios que a nova situação de adaptação lhe coloca.

Ao definir sua posição teórica, Piaget $(1977)^{1}$ se auto-intitula um construtivista, em oposição a concepções empiristas e inatistas do conhecimento. Dessa forma, o conhecimento é fruto de uma interação e de ações mútuas indissociáveis entre sujeito e meio, não havendo, portanto ênfase nas experiências adquiridas (empirismo) e nem na bagagem hereditária (inatismo); mas na relação e interação entre esses dois elementos.

Somente esse dado, ainda que não fosse intenção do autor, influencia diretamente a ação educativa. Mesmo que de forma inconsciente, um professor age seguindo preceitos empiristas, inatistas ou construtivistas. É a partir das concepções que temos sobre como nosso aluno age sobre o conhecimento que organizamos nossa prática educativa.

Assim concebida, a inteligência infantil não poderia ser tratada, muito menos que a inteligência adulta, por métodos pedagógicos de pura receptividade. Toda inteligência é uma adaptação; toda adaptação comporta uma assimilação das coisas do espírito, como também o processo complementar de acomodação. Logo, qualquer trabalho de inteligência repousa num interesse. (PIAGET, 1998, p.162)

Nos textos que escreve sobre educação, Piaget afirma que o grande objetivo dessa área do saber é a autonomia intelectual e moral. Autonomia no sentido do próprio governo, daquele que busca, que investiga, que testa, que não se deixa dominar; intelectual e moralmente, pois há influência mútua dos vários aspectos do desenvolvimento.

De fato, a educação tradicional sempre tratou a criança como um pequeno adulto, um ser que raciocina e pensa como nós, mas desprovido simplesmente de conhecimentos e de experiência. Sendo a criança, assim, apenas um adulto ignorante, a tarefa do educador não era tanto a de formar o pensamento, mas sim de equipá-lo; as matérias fornecidas de fora eram consideradas suficientes ao exercício. O problema é todo outro quando se parte da hipótese das variações estruturais. Se o pensamento da criança é qualitativamente diferente do nosso, o objetivo principal da educação é compor a razão intelectual e moral; como não se pode moldá-las de fora, a questão é encontrar o meio e os métodos convenientes para ajudar a criança a constituí-la ela mesma, isto é, alcançar no plano intelectual a coerência e a objetividade e no plano moral a reciprocidade. (PIAGET, 1998, p. 163).

\footnotetext{
1 "Piaget on Piaget": vídeo dirigido e encenado pelo próprio Piaget. Produzido pela Yale University $\mathrm{mm} / \mathrm{opt} / \mathrm{c} / 40$ '.
} 
Discutindo sobre questões educacionais e pedagógicas, Piaget afirma que o direito à educação deve ser entendido não somente como o direito de acesso à escola, mas o direito a uma educação de qualidade que promova o desenvolvimento do indivíduo globalmente, nos seus aspectos cognitivos, sociais e afetivos (PIAGET, 1972). Essa discussão ainda nos parece bastante atual. Além disso, o autor destaca a importância dos métodos ativos na educação em oposição aos métodos passivos, enfatizando que a ação do aluno, numa perspectiva construtivista, torna-se essencial. Métodos ativos opõem-se a métodos passivos que concebem os alunos como meros receptores de informações que apenas reproduzem, decoram, copiam etc.

Em nosso entendimento, um educador necessita compreender tais questões, refletir sobre elas e, sobretudo ter suporte teórico e estudo continuado que lhe permitam a autonomia das decisões na sala de aula e a coerência entre as ações e o referido suporte. Não entraremos nesse artigo na discussão sobre os problemas da formação dos educadores em nosso país que, sem dúvida, contribuem para a ocorrência dos problemas que levantaremos aqui, mas adotaremos a perspectiva de que o bom professor é necessariamente fundamentado e reflexivo, buscando continuadamente seu aperfeiçoamento, sejam em leituras, trocas com colegas, cursos, congressos etc. Concordamos com Piaget quando esse aponta que:

A razão geral de tal estado de coisas está naturalmente em que o mestre-escola não chega a ser considerado pelos outros - e, o que é pior, nem por ele mesmo - como um especialista, quer do ponto de vista das técnicas, quer do da criação científica. Apenas aparece como um simples transmissor de um saber ao nível de cada um. Em outras palavras, conta-se que um bom mestre contribua com o que dele se espera, porquanto possui uma cultura geral elementar e algumas receitas aprendidas, que lhe permitem inculcá-la na mente dos alunos. (PIAGET, 1998, p.20).

Nesse sentido, para Piaget o ensino abarca três problemas centrais que devem ser o alvo do educador: $1^{\circ}$ - Qual o objetivo desse ensino? Aprender a aprender, inovando e criando ou aprender a repetir? (note-se que Piaget já trazia para discussão algo que hoje é apontando como tremendamente inovador); $2^{\circ}$ - Como atingir os objetivos a que se propõe, ou como formar um espírito de descoberta e de controle ativo? $3^{\circ}$ - Conhecer as leis do desenvolvimento mental e encontrar os métodos mais adequados para obter a formação educativa desejada.

Essas questões nortearam nosso trabalho e foi pensando nelas que dirigimos o desenvolvimento de uma disciplina a respeito da teoria de Piaget. 


\section{PIAGET NO CURSO DE PEDAGOGIA}

Ao trabalharmos no curso de Pedagogia numa Instituição de Ensino Superior particular no interior do estado de São Paulo, tivemos a oportunidade de ministrar uma disciplina intitulada "Princípios da Psicogênese Aplicada à Educação". Essa disciplina estava inserida na grade curricular das disciplinas do curso de Pedagogia e constituía o grupo de matérias básicas e obrigatórias a todos os alunos. O curso formava pedagogos habilitados em Magistério da Educação Infantil e Supervisão Educacional. A forma de organização curricular proposta que se apresentava no projeto é o currículo-integração, no qual está presente a idéia de interdisciplinaridade. Os alunos atendidos constituíam, na sua maioria, mulheres provenientes do ensino público que trabalham em escolas particulares e/ou públicas.

A ementa da disciplina bem como seus objetivos e conteúdo podem ser assim descritos:

Ementa - Conceitos fundamentais para a compreensão da epistemologia genética. A teoria da equilibração e o dinamismo da formação das estruturas mentais. As determinações do sujeito epistêmico. Vantagens da utilização dos conceitos basilares da epistemologia genética.

Objetivos - Estudar os conceitos fundamentais da epistemologia genética de Jean Piaget (processo, fatores e estágios de desenvolvimento). Analisar as implicações pedagógicas decorrentes desse estudo.

Conteúdo Programático:

- Sujeito e objeto de conhecimento em psicologia genética;

- Interação e construção;

- A construção das estruturas da inteligência na criança e os fatores do desenvolvimento;

- Tipos de experiência e abstrações envolvidas;

- A adaptação e o processo de equilibração;

- A aprendizagem e o desenvolvimento;

- Piaget e a educação.

Dessa forma, a disciplina foi pensada com o objetivo de estudar e embasar o aluno na teoria psicogenética de Jean Piaget. Desde a formação da primeira turma de pedagogia em 1999 até 2003 o trabalho foi realizado com 10 turmas diferentes, nos períodos matutino e 
noturno. O que buscamos nesse percurso foi pensar em como a teoria piagetiana poderia ser útil ao pedagogo que estava sendo formado, procurando fornecer subsídios para sua atuação.

Os conteúdos versaram sobre questões básicas da teoria. Isso se deu em razão do próprio tempo disponível para o trabalho: 72 horas divididas em 4 horas semanais e em função dos alunos nunca terem ouvido falar de Jean Piaget. Destacamos também que alguns tiveram contanto com a teoria nos cursos de magistério no ensino médio, mas pelo que vimos era algo muito parecido com o senso comum da teoria, que corresponde àquela velha idéia de "todos mais ou menos sabem ou já ouviram falar".

Inicialmente os conceitos tratados foram: a idéia de construção, a oposição piagetiana ao inatismo e empirismo e a contextualização da obra piagetiana - qual seja - um pesquisador tentando encontrar respostas biológicas para a construção da inteligência.

Em seguida, prosseguíamos com o estudo dos clássicos estágios piagetianos. Esse estudo que é visto como ultrapassado e antigo, nos parece fundamental, principalmente porque o conhecimento desses períodos do desenvolvimento em momento algum se dava desvinculado da prática pedagógica.

Dessa forma, os alunos não tiveram simplesmente contato com as características básicas do período sensório-motor, pré-operatório, operatório concreto e operatório formal isso aliás, de certa forma, freqüentemente é feito em cursos de Pedagogia, Psicologia e áreas afins. O que se procurou realizar foi um estudo mais aprofundado das ações dos professores em função de tais características, não só em relação ao desenvolvimento cognitivo, mas também social e afetivo, buscando mostrar aos futuros pedagogos que as decisões sobre planejamentos, objetivos, atividades, avaliação, materiais etc, que eles deverão tomar ao atuarem como professores, podem favorecer ou impedir o desenvolvimento dos seus alunos.

A cada estágio estudado, buscávamos refletir sobre como os professores agem e/ou podem vir a agir considerando as peculiaridades do desenvolvimento. Quais ações respeitam ou favorecem a construção do conhecimento pelo aluno? Quais as necessidades infantis que o professor não pode desconsiderar? Como o projeto da escola e a postura dos profissionais que nela atuam pode ser coerente ou não com esse referencial teórico?

Durante o trabalho, no encerramento do curso, aplicávamos um questionário que objetivava avaliar a disciplina nos seguintes aspectos: conteúdo, avaliação do professor e 
auto-avaliação discente. No presente artigo, deteremo-nos na avaliação do conteúdo trabalhado.

Em relação ao conteúdo, o questionário era composto das seguintes perguntas:

1) Qual a contribuição que esse curso trouxe para você?

2) Você recomendaria esse curso a um amigo? Por que?

3) O que você mudaria nesse curso?

4) Destaque os pontos positivos do curso.

5) Destaque os pontos negativos do curso.

Os alunos eram convidados a preencher o material livremente, sem identificação, informados que os dados obtidos auxiliariam na reformulação/aperfeiçoamento do curso. Ao longo dessas 10 turmas o questionário foi respondido por 278 alunos, sempre na última aula depois da entrega das notas finais do semestre.

\section{RESULTADOS}

As respostas foram analisadas qualitativamente e quantitativamente. Para algumas questões, como por exemplo, a questão 2, a análise foi predominantemente quantitativa, para outras questões como a número 1, predominantemente qualitativa, e para algumas questões como as de número 4 e 5 recorremos aos dois tipos de análise. Para avaliação qualitativa, fizemos a leitura, interpretação e categorização das respostas conforme a Análise de Conteúdo proposta por Bardin (1977).

\section{Questão 1}

Em relação à questão 1 "Qual a contribuição que esse curso trouxe para você?", as respostas centraram-se nos pontos abordados durante as aulas, principalmente nas reflexões sobre o uso da teoria na prática docente e sobre o desenvolvimento infantil. Os alunos levantaram temas que marcaram sua experiência durante o curso, indicando pontos significativos apreendidos durante as aulas, textos, dinâmicas e demais atividades. 
Todos os 278 alunos escreveram alguma contribuição deixada pela disciplina, não havendo, portanto, nenhuma resposta em branco ou negativa do tipo: "nenhuma contribuição".

Apresentaremos algumas respostas comuns, comentando o exercício de reflexão teoria-prática-teoria-prática que buscamos ao longo dos encontros.

Para a avaliação dessas respostas identificamos três categorias que retratam a maioria dos temas levantados pelos alunos. Apesar de constituírem três categorias diferentes, é possível perceber que a mesma resposta pode enquadrar-se em duas categorias ou até em todas simultaneamente, pois aquilo que buscamos no trabalho realizado junto a esses alunos também retrata a não separação entre teoria e prática na formação do professor. Vejamos as respostas:

Categorias de respostas para a pergunta 1:

- Ações didáticas a partir do referencial teórico

Nessa categoria encontram-se os temas que se relacionam diretamente à influência do estudo da teoria para a prática realizada em sala de aula, entre eles:

\section{Construtivismo e educação}

"Hoje entendo o papel do professor no construtivismo, não é de observador. ${ }^{2 "}$

Essa é uma das grandes distorções que a teoria piagetiana sofreu e vem sofrendo até hoje além de ser uma das respostas que mais apareceu nos questionários. Ao lerem Piaget, muitos interpretam o processo de construção espontâneo que o autor defende como um processo inatista ou maturacionista. Essa idéia permeia as discussões escolares e retrata a falta de conhecimento da obra piagetiana, o que já mencionávamos no início desse artigo. Nesse sentido, é muito comum vermos práticas baseadas em pouquíssimas intervenções, concepções equivocadas de avaliação e de correção, julgamentos errôneos sobre limites e desenvolvimento moral etc.

\footnotetext{
2 Todas as respostas foram transcritas aqui exatamente como redigidas pelos alunos.
} 
A grande discussão que Piaget apresenta sobre o construtivismo em relação à educação não é a da espera passiva da construção pelo aluno, mas justamente a idéia de método ativo "... de que todos falam e que bem poucos educadores aplicam realmente de forma eficaz" (PIAGET, 1998 p. 130). Tal método baseia-se, sobretudo no princípio de que é preciso inventar para compreender, reconstruindo, criando e não apenas repetindo. Dessa forma, o aluno é o centro do processo, mas não se pode esquecer da interação, da relação entre o sujeito e o meio que desencadeia as múltiplas equilibrações e reequilibrações individuais. O professor, nesse processo, como parte integrante do meio, é aquele que abre ou fecha oportunidades, que cria ou não possibilidades de ação, que desafia ou não o pensamento; portanto, tem um papel essencial.

\section{O professor que considera o desenvolvimento dos seus alunos}

"Durante as aulas fui me sentindo mais responsável sobre meus alunos, vendo a força que tenho sobre eles"

"É preciso considerar como a criança pensa, ao fazer meus planejamentos estou sempre pensando nisso"

Esses pensamentos retratam uma reflexão feita exaustivamente em aula sobre como o educador pode favorecer ou impedir o progresso do seu aluno, ou seja, é preciso conhecer as leis que regem o desenvolvimento humano para saber atuar na direção desse desenvolvimento. Nesse sentido, é importante que o educador saiba que ele favorece ou impede consideravelmente as oportunidades de construção do discente. Vale observar o que Piaget assinalava sobre isso: "... é preciso que o mestre-animador não se limite ao conhecimento da sua ciência, mas esteja muito bem informado a respeito das peculiaridades do desenvolvimento psicológico da inteligência da criança ou do adolescente..." (1972, p.15).

Uso de materiais:

"Comecei a perceber que material devo colocar à disposição dos alunos"

"Agora sei o que é realmente trabalhar no concreto" 
Gostaríamos de destacar que essas questões foram bastante trabalhadas, pois normalmente constituem-se em aspectos "conhecidos" da teoria, mas não compreendidos e nem pensados/refletidos. O que significa concreto? $\mathrm{O}$ professor pode respeitar o desenvolvimento da inteligência no período operatório concreto? De que forma?

A reflexão necessita ocorrer, pois percebemos que muitos acreditam que os materiais devam ser colocados na sala simplesmente e deixados lá, para que os alunos manipulem. É preciso refletir sobre como esse material deve ser explorado pela criança a partir das solicitações do professor. Algo também muito comum que ocorre e que vários alunos nos relataram, é que os professores entendem a questão do concreto sob o próprio ponto de vista e não o da criança. Assim, estes professores utilizam-se de demonstrações com materiais concretos, ou dirigem a manipulação dos alunos coletivamente, sem desafiar o pensamento da criança. A esse respeito o próprio Piaget nos alertava:

Inútil apelar para as réguas Cuisenaire, de que já disse que podem dar lugar a utilizações as mais opostas, sendo umas realmente operatórias se a criança descobre por si mesma as diversas operações que permitem as manipulações espontâneas, e as outras essencialmente intuitivas ou figurativas se limitam a demonstrações exteriores e à leitura de figurações acabadas. (1988, p. 79).

- Considerar as especificidades de ser criança

Embora algumas respostas se assemelhem a itens tratados na categoria anterior, optamos por colocar aqui aquelas que apontaram para uma preocupação com as especificidades e necessidades infantis, em concordância com a teoria de Piaget que aponta e explica um pensamento infantil qualitativamente diferente do adulto.

"Quando minha diretora diz que tenho que ficar dando materiais apostilados e atividades de alfabetização para meus alunos da pré-escola, digo prá ela que eles precisam brincar também e desenvolver outras coisas importantes”.

"Sempre trabalhei com o ensino fundamental e hoje vejo a importância que eu nunca dei para a educação infantil. É uma criança que tem qualidades diferentes e a gente tem que saber respeitar”. 
A esse respeito vale dizer que concordamos com Assis (1989), quando diz que a criança na pré-escola tem o direito de ter uma educação que permita o seu desenvolvimento em todos os seus aspectos e não somente o cognitivo, podendo desenvolver tudo aquilo que deve desenvolver nessa etapa da sua vida. Isso acaba remetendo a uma outra idéia, bastante discutida que trata do olhar do adulto sobre a criança, ou seja, daquele que olha para a infância como um simples degrau para a posteridade e não como um momento rico que precisa ser vivido e explorado. Nesse sentido, o que se vê atualmente é uma pressa grande das escolas e dos pais em alfabetizar, em preparar as crianças para etapas posteriores, sobrecarregando-as com atividades e desrespeitando suas necessidades. Esse olhar, reflete-se também nas produções artísticas infantis que acabam sendo avaliadas não mais conforme aquilo que as crianças podem e sabem fazer em alguns momentos, mas de acordo com o que é belo e aceitável no "mundo dos adultos". Esses temas apareceram em algumas respostas:

"Aprendi que meus alunos só poderão criar se eu não limitar isso dando desenhos mimeografados. E que eu não tenho que ficar olhando para os desenhos deles querendo que se pareçam com os meus e com os de outros adultos”.

“Hoje depois das suas aulas paro de brigar com meus alunos porque eles estão conversando e procuro deixá-los trabalhar mais em grupo, pois sei que eles precisam disso. Não fico querendo uma sala silenciosa e disciplinadíssima, pois onde tem troca, decisões em grupo não dá prá ter silêncio absoluto”.

"Foi interessante ver porque a criança tem que brincar. Ela precisa é uma necessidade dela. Isso é bom saber".

Tratando especificamente da questão do brincar, gostaríamos de salientar que na atualidade há muita produção teórica sobre jogos e brincadeiras, mas não vemos nossas escolas e nossos professores realmente compreenderem a questão e permitirem que seus alunos brinquem, nem entenderem que ao brincar a criança está aprendendo e se desenvolvendo. Normalmente, os jogos livres só são permitidos em momentos de descanso do professor, opondo-se aos momentos de trabalho e aprendizagem. A esse respeito, vale observar o que Piaget declarava:

Deixar as crianças jogarem é então uma higiene mental, tão proveitosa e fácil como deixá-las respirar ar puro é uma higiene física. Se elas sofrem uma tristeza, ou uma 
decepção uma afeição mal correspondida ou uma desconfiança delas mesmas, elas inventam as situações lúdicas mais próprias para superá-las, melhor do que poderia fazer um adulto inábil. (1943/2003, p.19).

- Referencial teórico na própria formação

"Entendo a importância de conhecer uma teoria, não via ligação de nada com a sala de aula”.

No nosso entendimento, essa categoria traz uma resposta que poucos alunos apresentaram, mas que era nosso grande objetivo. Assim, conscientizar o estudante sobre a importância do estudo do referencial teórico e como este influencia/deve influenciar sua prática diária, implica na compreensão da necessidade da formação continuada, da busca constante e da atualização sistemática. Nosso sonho é que trabalhando assim, possamos despertar em nossos alunos estas necessidades e também um espírito crítico e pesquisador, a fim de que a fundamentação norteie suas decisões e que suas ações sejam fontes de contínuas reflexões.

Ao trabalharmos com formação de professores não somente em cursos de Pedagogia, mas também em escolas ministrando palestras, oficinas, observamos que a ausência desse espírito crítico e dessa formação faz dos educadores verdadeiros reféns de práticas decididas em gabinetes, de imposições da direção e orientação da escola, de modismos educacionais e até mesmo de palpites e exigências dos pais dos alunos. Sobre isso vale dizer que quando o professor compreende essas questões passa a se perceber como um eterno aprendiz, que também constrói e reconstrói conhecimento. Piaget também alertava para isso ao afirmar:

Em particular a preparação psicológica, tão indispensável aos professores primários cujo ensino é, deste ponto de vista, visivelmente mais complexo e difícil que um ensino secundário -, não pode realizar-se eficientemente a não ser em ligação com os núcleos de pesquisa universitários, onde se encontram em ação os especialistas. Só se aprende realmente a psicologia infantil colaborando em pesquisas novas e particularmente em experiências, sem contentar-se com exercícios ou trabalhos práticos que só se referem a resultados conhecidos; ora, os professores podem aprender a se tornarem pesquisadores e a ultrapassarem o nível de simples transmissores. (1988, p. 131).

Nesse sentido, destacamos que durante o curso, tivemos o cuidado de sempre apresentar aos alunos pesquisas e trabalhos que vem sendo realizados e que constituem-se em aplicações e estudo novos sob o enfoque piagetiano, em várias áreas, e que muito contribuem para o trabalho do professor em sala de aula, apenas para citar alguns: BORGES, 2001; KAMII, 1990, 1991; SARAVALI, 1999; VINHA, 1997; ZAIA, 1996. 
Antes de passarmos às demais questões, gostaríamos de salientar que durante as aulas ao discutirmos sobre o papel da escola e do educador, muitos alunos traziam para o debate não somente suas ações atuais com seus próprios alunos, mas também como foram educados pelos seus professores e até mesmo pelos próprios pais. Essas reflexões ocorriam principalmente quando o conteúdo abordado tratava do desenvolvimento moral e do processo de criação, da representação e do desenho infantil. Ao analisarmos os questionários nos surpreendemos com o fato de isso não ter aparecido nas respostas dos nossos alunos.

Em relação à reflexão sobre a educação familiar, vale dizer que algumas alunas que eram mães costumavam trazer questões/comentários acerca do que estavam vivendo em casa. Sobre isso uma aluna respondeu à questão 1 assim: "Sou uma mãe diferente depois dessas aulas, tomo cuidado com o que vou falar e não dou mais castigo, só uso a reciprocidade. Acho que está funcionado."

Questão 2

A primeira parte da questão "Você recomendaria esse curso a um amigo?" Teve sim em $100 \%$ das respostas. Ao justificarem suas razões, na segunda parte da pergunta, a maioria os alunos apresentou respostas que dividimos em duas grandes categorias:

- Importância do conhecimento da teoria de Piaget pelo professor

Nessa categoria encontram-se as respostas que apontaram para a necessidade do professor ter conhecimento da teoria, algumas destacando até um estudo mais aprofundado.

"Um professor precisa saber isso que aprendemos aqui".

"Como pode um professor ir para sala de aula sem conhecer seus alunos?".

"Recomendaria porque aquilo que a gente vê no magistério é muito pouco".

"Eu recomendaria até que tivéssemos mais aulas".

"Eu recomendaria para a diretora da escola da minha filha".

Essa resposta, de apenas uma aluna, mas que quisemos colocar aqui, retrata que a reflexão estava sendo feita de tal modo que levava o aluno a questionar várias formas de atuação pedagógica e de relação adulto/criança com as quais convivia.

- Relação entre teoria e prática 
"Eu senti que nessa disciplina pude aprender coisas importantes para usar em sala de aula"

"Nesse curso eu vi ação e não somente teoria"

Apesar de semelhante à outra categoria, entendemos que aqui os alunos levantaram a questão de poderem perceber como a teoria pode e deve estar vinculada à prática. Isso não significa que nós professores devamos proceder à discussão de receitas, condutas prontas e acabadas; mas sim levar os alunos a descobrirem esses caminhos à luz do referencial teórico, a fim de que eles próprios possam, a partir de então, refletir e decidir com autonomia e fundamentação.

Questão 3

Para a pergunta: "O que você mudaria nesse curso?" 95\% dos alunos responderam: "nada" ou "está tudo bem". Dos 5\% que sugeriram alterações, encontramos dois tipos de respostas.

No primeiro tipo, que constituiu a maioria, os alunos disseram que gostariam de ter mais prática, como por exemplo:

"No início estava muito difícil, aquela parte de impirismo, inativismo, assimilação e acomodação. Depois melhorou, acho que você devia dar menos teoria".

Vale dizer que o curso iniciava-se com uma carga teórica maior e à medida que cada estágio do desenvolvimento era estudado, as relações com a ação do educador eram discutidas e exploradas. Tal resposta, apesar de indicar a visão de uma minoria do grupo, a nosso ver, mostra bem como nossos alunos e professores em formação ainda pecam pela busca do caminho mais fácil, aquele que exige menos reflexão e estudo, aquele que traz "tudo pronto" para ser aplicado em aula. É tão mais fácil comprar um livro didático e segui-lo; é tão mais fácil usar o material apostilado, enfim é muito mais fácil reproduzir ao invés de criar.

No segundo tipo de resposta, apresentada por uma aluna apenas, mas que julgamos importante abordar, encontramos a seguinte afirmação:

"Poderíamos ver outros autores, só Piaget, só Piaget cansa”. 
É importante ressaltar, e talvez isso não tenha ficado claro para a aluna, que o objetivo da disciplina era estudar as contribuições da psicologia genética para o ensino. Nosso objetivo, portanto, não era abordar outro autor. Essa questão nos remete ao fato de que, muitas vezes, vemos nos cursos de Pedagogia um interesse grande em construir uma grade que contemple diferentes posições epistemológicas, tratando de diferentes autores (isso pode ocorrer até numa mesma disciplina). Isso nos parece interessante, sem, contudo esquecer que o aprofundamento também é importante a fim de que o aluno possa ter acesso às idéias do autor pelo próprio autor, permitindo uma construção mais lenta e uma reflexão mais elaborada. Muitas vezes, percebemos que ao tratar de muitas teorias, os cursos acabam propiciando um estudo superficial mais baseado no senso comum do que naquilo que realmente o autor escreveu e defendeu.

Questão 4

Na questão 4 que se refere aos pontos positivos do curso, a maioria das respostas não abordou o conteúdo mas a postura da professora e a relação entre educador-educando que ali se estabeleceu. Em relação ao conteúdo, as categorias encontradas foram duas que se assemelham em muito ao que foi abordado anteriormente. A primeira refere-se ao conhecimento da obra piagetiana:

\section{"Conhecer Piaget"}

"Conhecer construtivismo que eu já tinha visto mas percebo que não eram bem aquilo."

A segunda, que constituiu a maioria, refere-se às oportunidades de reflexão sobre a prática em sala de aula:

"É um curso que tem prática"

"Dá para ver o que pode ser feito com a criança"

Questão 5

Nessa questão, o padrão de respostas foi muito semelhante ao da questão 3. Assim 95\% dos alunos afirmaram que não havia pontos negativos. Dos 5\% restantes, os pontos 
negativos foram correspondentes, justamente, ao que havia sido sugerido na questão 3, ou seja, "Ter menos teoria e mais prática" e "Estudar outros autores".

\section{CONSIDERAÇÕES FINAIS}

O que objetivamos nesse trabalho foi refletir acerca da importância da fundamentação do educador para sua prática e qual a contribuição que a teoria piagetiana oferece nesse aspecto. Nossa reflexão embasou-se na avaliação de uma disciplina sobre a teoria piagetiana num curso de Pedagogia.

Ao ministrarmos esse curso, observamos as reações e reflexões dos nossos alunos e obtivemos junto deles uma avaliação mais sistematizada mediante o preenchimento de um questionário.

Os dados retirados dos questionários, ao nosso ver, confirmaram os constantes feedbacks que recebíamos em sala. Durante as aulas acompanhamos o crescimento das discussões que se tornaram mais reflexivas e aos poucos se remetiam ao suporte teórico que estava sendo estudado.

Os debates sobre a prática dos próprios alunos no seu cotidiano e a reflexão sobre as formas como foram educados, pelos seus professores e pelos próprios pais, foram para nós bastante interessantes do ponto de vista do crescimento pessoal e profissional de todos. Nesse sentido, observamos que os temas trabalhados trouxeram para os discentes contribuições para sua atuação em sala de aula, sua vida pessoal como mãe e/ou filho, para uma reflexão sobre a própria organização escolar e o projeto pedagógico da escola, bem como uma reflexão direta sobre o trabalho com seus alunos.

Assim como Piaget (1972) defendia, acreditamos também que de nada adianta um aumento na oferta de vagas e garantias ao acesso se não se discute a qualidade da educação oferecida. Ora, essa qualidade perpassa necessariamente pela qualidade da formação do educador.

Além de uma boa formação, é necessário que o educador tenha comprometimento com o seu aluno; compreendendo que o discente deve ser a prioridade no processo. Portanto, o professor precisa conhecer esse sujeito, precisa saber como ele pensa, quais são suas 
necessidades, como se desenvolve a fim de orientar as ações pedagógicas em função disso, caso contrário não há sentido para a educação que venha a ser proposta.

Em tempos atuais, em que muito podemos questionar sobre a qualidade da educação básica e quando muitos defendem uma reforma, não podemos esquecer que pensar no aluno é importante para pensar numa transformação e numa mudança.

Para os cursos de Pedagogia que não mais trabalham com a organização curricular em forma de disciplina, mas com eixos temáticos, acreditamos que o estudo dos conceitos de inteligência, desenvolvimento, aprendizagem, interação, infância, moral, para citar apenas alguns, sob o enfoque piagetiano são essenciais para a formação do futuro pedagogo.

Ousamos querer estar contribuindo diretamente para a qualidade da formação de nossos futuros professores.

\section{REFERÊNCIAS}

ASSIS, Orly Z. Mantovani de. Uma nova metodologia de educação pré-escolar. 6.ed. São Paulo: Biblioteca Pioneira de Ciências Sociais, 1989. 55p.

BARDIN, L. Análise de conteúdo. Tradução: Luís Antero Reto e Augusto Pinheiro. Lisboa: Edições 70, 1977. 225p.

BORGES, Roberta. A construção da noção de família em crianças pré-escolares. 2001. Dissertação (Mestrado) -Faculdade de Educação, Universidade Estadual de Campinas, 2001.

KAMII, Constance. A criança e o número: implicações educacionais da teoria de Piaget para a atuação junto a escolares de 4 a 6 anos. Tradução: Regina de Assis. 11.ed. Campinas: Papirus, 1990. 124p.

KAMII, Constance;DEVRIES, Rheta. Jogos em grupo na educação infantil: implicações da teoria de Piaget. Tradução: Marina Carrasqueira. São Paulo: Trajetória Cultural, 1991. 355p.

PIAGET, J. O jogo e a higiene mental da criança, 1943. In: ENCONTRO NACIONAL DE PROFESSORES DO PROEPRE, 20, 2003, Campinas. Anais... Campinas: Faculdade de Educação/UNICAMP, 2003. p.17-19

. O nascimento da inteligência na criança. Tradução: Álvaro Cabral. Rio de Janeiro: LTC, 1966. 389p. 1972. 80p.

Para onde vai a educação? Tradução: Ivette Braga. Rio de Janeiro: José Olympio, 
Psicologia e pedagogia. 9.ed. Tradução: Dirceu Lindoso e Rosa Silva. Rio de Janeiro: Forense, 1988. 184p.

SARAVALI, E.G. As idéias das crianças sobre seus direitos: a construção do conhecimento social numa perspectiva piagetiana. 1999, 243f. Dissertação (Mestrado em Psicologia Educacional) - Faculdade de Educação, Universidade Estadual de Campinas, Campinas, 1999.

VINHA, T. O educador e a moralidade infantil numa perspectiva construtivista. 1997. 1104f. Dissertação (Mestrado em Psicologia Educacional) - Faculdade de Educação, Universidade Estadual de Campinas, Campinas, 1997.

ZAIA, L. L. A solicitação de meio e a construção das estruturas operatórias em crianças com dificuldades de aprendizagem. 1996. 255f. Tese (Doutorado em Psicologia Educacional) - Faculdade de Educação, Universidade Estadual de Campinas, Campinas, 1996. 